\title{
(Bio)degradable Ionomeric Polyurethanes Based on Xanthan: Synthesis, Properties, and Structure
}

\author{
T. V. Travinskaya, A. N. Brykova, Yu. V. Savelyev, N. V. Babkina, and V. I. Shtompel \\ Institute of Macromolecular Chemistry, NAS of Ukraine, Kharkovskoe Shosse 48, Kiev 02160, Ukraine \\ Correspondence should be addressed to T. V. Travinskaya; travinskaya-tamara@rambler.ru
}

Received 1 June 2017; Revised 21 July 2017; Accepted 9 August 2017; Published 24 September 2017

Academic Editor: Shida Miao

Copyright (c) 2017 T. V. Travinskaya et al. This is an open access article distributed under the Creative Commons Attribution License, which permits unrestricted use, distribution, and reproduction in any medium, provided the original work is properly cited.

\begin{abstract}
New (bio)degradable environmentally friendly film-forming ionomeric polyurethanes (IPU) based on renewable biotechnological polysaccharide xanthan (Xa) have been obtained. The influence of the component composition on the colloidal-chemical and physic-mechanical properties of IPU/Xa and based films, as well as the change of their properties under the influence of environmental factors, have been studied. The results of IR-, PMS-, DMA-, and X-ray scattering study indicate that incorporation of Xa into the polyurethane chain initiates the formation of a new polymer structure different from the structure of the pure IPU (matrix): an amorphous polymer-polymer microdomain has occurred as a result of the chemical interaction of Xa and IPU. It predetermines the degradation of the IPU/Xa films as a whole, unlike the mixed polymer systems, and plays a key role in the improvement of material performance. The results of acid, alkaline hydrolysis, and incubation into the soil indicate the increase of the intensity of degradation processes occurring in the IPU/Xa in comparison with the pure IPU. It has been shown that the introduction of Xa not only imparts the biodegradability property to polyurethane, but also improves the mechanical properties.
\end{abstract}

\section{Introduction}

Problem of environmental pollution with polymeric waste has shown a clear need for ecologically friendly materials based on renewable resources: vegetable oils and natural polymers, in particular, polysaccharides, which results in the development of a new trend in polymer chemistry, creation of sustainable biodegradable polymers having a wide range of applications [1-4]. Several methods of incorporating polysaccharides into the polyurethanes are discussed depending on the desired final properties of the polyurethane [5]. Due to the success of biotechnologies, a particular attention in modern chemistry of biodegradable polymers is paid to microbial polysaccharides (exopolysaccharides), which are climate and season independent. One of the leading places in this line belongs to xanthan, an extracellular polysaccharide of the bacteria Xanthomonas campestris. Xanthan molecules are prone to the self-association in aqueous solutions; a rise of solution ionic strength or polysaccharide concentration results in gel formation $[6,7]$. Xanthan provides the synthetic polymers, in particular, polyurethanes, with ability to degrade under the influence of natural factors. It was shown that the chemical bond between synthetic and natural components played a crucial role in giving to the synthetic polymer biodegradability, opposed to mechanical mixtures, where only the natural component decomposed with time $[8,9]$. Aqueous film-forming polyurethane dispersions have found diverse applications as finishing, impregnating, stiffener, protective materials, and adhesives in leather, textile, and furniture industry $[10,11]$. The synthesis and characterization of novel aqueous polyurethane dispersions derived from plant oil and starch with the use of dimethylolpropionic acid as internal emulsifier which allows us to incorporate hydrophilic groups into the polymer chain and achieve stable selfemulsifying dispersions are discussed in [12-14]. It should be noted that the synthesis of degradable polyurethanes based on renewable feedstock is one of developing branches of green polyurethane chemistry. Such materials may be used as packaging, finishing, impregnating, stiffener, protective materials, and adhesives in leather, textile, and furniture industry, biologically active substances in agriculture. A distinctive feature of degradable polymers is to preserve 
the necessary operational parameters during the time of their use in combination with accelerated degradation under the influence of various natural factors after the expiration. Microorganisms are the main biological systems which destroy the polymeric compounds. The ability of polymers to degrade and be assimilated by microorganisms depends on a number of their characteristics: the chemical structure of the polymer, molecular weight, branching of macrochain, and supramolecular structure [15]. The aim of the latest developments in the field of degradable polymers is to establish the common principles in selecting the components for synthesis of polymer which combine a high level of performance with the (bio)degradation ability and knack of adjusting the (bio)degradation processes to ensure fast and safe (bio)degradation of polymer materials at the expiration of their working time. The paper considers the synthesis and complex study of "composition, structure, properties, and (bio)degradation ability" relationship of structurally modified polymeric materials based on polyurethane ionomer and microbial exopolysaccharide xanthan.

\section{Experimental}

2.1. Materials. Hexamethylene diisocyanate (HMDI) (Merck), polyoxytetramethylene glycol (POTMG 1000), dimethylolpropionic acid (DMPA), triethylamine (TEA), and $\mathrm{Xa}$ in the form of powder (Brookfield viscosity of $1 \%$ solution, according to Certificate of analysis, amounts $959 \mathrm{cps})$ were purchased from Aldrich and used as received; acetone was purchased from Fluka.

2.2. Preparation of Xanthan Containing Ionomer Polyurethane. Xanthan containing ionomer polyurethanes (IPU/Xa) in the form of aqueous dispersions was prepared by the reaction of an isocyanate precursor based on POTMG and HMDI with DMPA as ion centers carrier, taken in a molar ratio of $1: 2: 0.6$. The reaction time for the isocyanate precursor formation was $2 \mathrm{~h}$ at $80^{\circ} \mathrm{C}$ until the NCO content reached the theoretical value to produce NCO-terminated prepolymer. The content of NCO groups was controlled according to [16]. Then, DMPA was added and reacted with prepolymer at $80^{\circ} \mathrm{C}$ for $1 \mathrm{~h}$. Suitable amount of acetone was added to the system to decrease the viscosity of reaction mixture. $\mathrm{Xa}\left(\mathrm{C}_{35} \mathrm{H}_{49} \mathrm{O}_{29}\right)_{n}$, was added to the reaction mixture in a form of dry powder (the reaction time was $1 \mathrm{~h}$ at $56^{\circ} \mathrm{C}$ ). Neutralization of the DMPA fragments' carboxyl groups of obtained IPU/Xa hard block was performed with TEA (the molar ratio of TEA:DMPA $=1: 1$ ). Next, a simultaneous elongation and water dispersion were carried out, followed by removal of acetone. Film-forming opalescent dispersions were then obtained by phase inversion. Polymer films were formed at room temperature on a Teflon disk, followed by drying in an oven at $65^{\circ} \mathrm{C}$ and in a vacuum oven at $55^{\circ} \mathrm{C}$ to constant weight.

IPU/Xa systems with different Xa weight concentrations, $5 \%, 10 \%$, and $30 \%$ (IPU/5Xa, IPU/10Xa IPU/30Xa), were prepared. IPU matrix was synthesized similar to IPU/Xa (using water as chain extender, without addition of $\mathrm{Xa}$ ) and has been selected as an object of comparison.

\subsection{Characterization}

2.3.1. $\mathrm{pH}$ Values. $\mathrm{pH}$ values were determined using $\mathrm{pH}$-meter "pH-150 M" (Russia).

2.3.2. Particle Size. Particle size measurements were determined from the turbidity spectrum using FEK-56M, according to [17].

2.3.3. Mechanical Properties. Measurements were performed using a tensile testing machine FU-1000 (VEB MWK "Fritz Heckert," Germany) at a tensile speed of $100 \mathrm{~mm} / \mathrm{min}$ and temperature $25^{\circ} \mathrm{C}$. The number of samples used in each measurement was three. Samples were prepared in a form of strips (width: $4 \mathrm{~mm}$, operating length: $2 \mathrm{~mm}$ ). Measurements were carried out in accordance with standard 14236-81; allowed error is $3 \%$.

2.3.4. Water Absorption. Preliminary weighed dry films of IPU matrix, IPU/Xa, were immersed in water for $24 \mathrm{~h}$, whereupon the excess water was removed with filter paper and samples were weighed. Water absorption $\left(W_{\mathrm{H} 2 \mathrm{O}}\right.$, wt.\%) was calculated according to $W_{\mathrm{H} 2 \mathrm{O}}(\%)=\left[\left(W_{w}-W_{d}\right) / W_{d}\right]$. $100 \%$, where $W_{w}$ and $W_{d}$ are weight of the films in a wet and dry state, correspondingly.

2.3.5. Degree of Hydrolysis in Acid and Alkali Medium. Degree of hydrolysis in acid and alkali medium was determined by evaluation of the weight change and physic-mechanical characteristics of the samples after hydrolysis. Preweighed samples were immersed in $0.1 \mathrm{~N}$ solution of $\mathrm{KOH}$ and $\mathrm{HCl}$ and kept in a thermostat for 30 days at $T=25^{\circ} \mathrm{C}$; afterwards the films were dried to constant weight with following weight control and tensile test.

2.3.6. IR Measurements. IR measurements were performed on Bruker "Tensor-37" Fourier transform infrared spectrometer in the region of wave numbers of $4500 \mathrm{~cm}^{-1}-500 \mathrm{~cm}^{-1}$. Samples' surfaces were studied by attenuated total internal reflection infrared spectroscopy.

2.3.7. Thermodestruction of Xa-Containing IPU. Thermodestruction of Xa-containing IPU was studied by pyrolytic mass spectrometry (PMS). A device consisting of a mass spectrometer MX-1321 for determination of the components of gas mixtures in the range of mass numbers of 1-4000 and of cells for linearly programmable pyrolysis in the temperature range $25-400^{\circ} \mathrm{C}$ was used. The sample was placed into the cell which was evacuated $\left(1.33 \cdot 10^{-4} \mathrm{~Pa}\right)$ for 30 minutes at $25^{\circ} \mathrm{C}$. The same pressure was maintained during the experiment. The heating rate was $(6 \pm 1)^{\circ} \mathrm{C} / \mathrm{min}$. The accuracy of determining the temperature of the sample was $\pm 1^{\circ} \mathrm{C}$. The ionization energy in the chamber of the mass spectrometer was $70 \mathrm{eV}$.

2.3.8. The X-Ray Diffraction Patterns. The wide-angle $\mathrm{X}$-ray diffraction patterns (WAXS) were recorded with 
TABLE 1: Properties of aqueous IPU/Xa dispersions and based films.

\begin{tabular}{|c|c|c|c|c|c|c|}
\hline \multirow[b]{2}{*}{ Xa content, \% } & \multicolumn{2}{|c|}{ Dispersion properties } & \multicolumn{3}{|c|}{ Film characteristics } & \multirow[b]{2}{*}{$\begin{array}{c}\text { Elongation at a break } \\
\text { point } \varepsilon, \%\end{array}$} \\
\hline & $\begin{array}{c}r_{\mathrm{av}^{*}}, \\
\mathrm{~nm}\end{array}$ & $\mathrm{pH}$ & $\begin{array}{c}\text { Water absorption, } 24 \\
\text { hours, } \%\end{array}$ & $\begin{array}{c}\text { Contact angle, } \\
\text { degree }\end{array}$ & $\begin{array}{c}\text { Tensile strength } \sigma \text {, } \\
\mathrm{MPa}\end{array}$ & \\
\hline 0 & 71 & 7,84 & 2,6 & 68 & 7,3 & 1100 \\
\hline 5,0 & 176 & 7,55 & 23 & 50 & 8,1 & 742 \\
\hline 10,0 & 272 & 7,17 & 65 & 45 & 16,9 & 530 \\
\hline 30,0 & 504 & 6,82 & 405 & 29 & 36,4 & 360 \\
\hline 100,0 & - & - & $\begin{array}{l}\text { The film was } \\
\text { dissolved }\end{array}$ & - & $* *$ & $* *$ \\
\hline
\end{tabular}

$r_{\mathrm{av}^{*}}$ : average particle radius, ${ }^{*}$ not applicable (the film is brittle).

X-ray diffractometer DRON-4-07 with roentgen schema made according to Debye-Scherrer method (transmission). Supramolecular structure was studied by small-angle X-ray diffraction (SAXS), using small-angle camera KRM-1 with flat-filled collimator, made according to Kratky method. All $\mathrm{X}$-ray measurements were carried out in $\mathrm{CuK}_{\alpha}$ radiation, monochromatic with Ni-filter at $T=22 \pm 2^{\circ} \mathrm{C}$.

2.3.9. Dynamic Mechanical Analysis (DMA). Dynamic mechanical measurements were carried out on a dynamic mechanical analyzer Q 800, TA Instruments in the tension mode at frequency of $10 \mathrm{~Hz}$ and heating rate of $2.0^{\circ} \mathrm{C} / \mathrm{min}$. The samples for DMA study were cut from the polymer films and had the following dimensions: length: $12.75 \mathrm{~mm}$, width: $4 \mathrm{~mm}$, and thickness: $0.3 \mathrm{~mm}$. The viscoelastic properties, that is, mechanical loss factor $(\tan \delta)$ and storage modulus $\left(E^{\prime}\right)$, were recorded as function of temperature. The glass transition temperature $\left(T_{g}\right)$ was determined by the position of the loss factor maximum.

\section{Results and Discussion}

3.1. Colloid-Chemical Properties. The composition, colloidchemical, and physic-mechanical properties of synthesized IPU/Xa dispersions and films are presented in Table 1.

The average particle size reports the degree of physical interaction of the constituent macromolecules and the dispersion medium. The introduction of Xa results in increasing of $r_{\mathrm{av}}$ owing to growth of the specific content of threedimensional $\mathrm{Xa}$ fragments in macromolecules (as previously was shown using the small Xa concentrations [18]), which, however, does not lead to a loss of dispersions' stability [19]. With increase of $\mathrm{Xa}$ content, the $\mathrm{pH}$ of dispersions is systematically reduced as a result of the presence in Xa of a large number of acid pyruvic cycles.

3.2. Water Absorption. The degree of swelling of polymer components and their affinity to water is one of the indices of decomposition rate of polymeric materials under the influence of environmental factors. The investigation of the hydrolytic stability of IPU/Xa has shown the increase of the water absorption up to a maximum value of $405 \%$ at $30 \%$ Xa content. Such increase may be due to the presence of free polar fragments (carboxyl and $\mathrm{OH}$ groups), which determine the hydrophilic properties of the polymer. Probably, a part of Xa hydrophilic hydroxyls involved in the formation of intermolecular bonds with the polar groups of IPUs remains unengaged, following an increase of their concentration in the surface layers and contributing to the elevation of the hydrophilicity degree and, normally, to decreasing of contact angle values (Table 1).

3.3. Physic-Mechanical Properties. The tensile strength of IPU/Xa films significantly increases as the $\mathrm{Xa}$ content increases and exceeds this index of the IPU matrix in 1-5 times (Table 1). The increase of tensile strength for the IPU/Xa films indicates the occurrence of the intermolecular interaction between IPU and Xa. The loss of elasticity is specified by decrease of the specific weight of the flexible IPU segments in polymer composition, which is in agreement with the IR spectroscopic data indicating the hydrogen association of ether oxygen of POTMG with $\mathrm{OH}$ groups of $\mathrm{Xa}$ and steric hinders effected by volume molecules of Xa.

3.4. IR Spectroscopy. IR spectra of IPU matrix (1), IPU/10Xa (2), and Xa (3) are presented in Figure 1(a). The IR spectrum of the initial $\mathrm{Xa}$ is characterized by intense absorption bands of stretching vibrations of $\mathrm{O}-\mathrm{H}$ bonds in the region of $3236-3613 \mathrm{~cm}^{-1}, 1031 \mathrm{~cm}^{-1}$, by peak of medium intensity of stretching vibrations of C-H bonds $\left(2926 \mathrm{~cm}^{-1}\right)$, an intense band with a frequency of $1736 \mathrm{~cm}^{-1}$, apparently corresponding to the vibrations of ester groups. IPU matrix shows all characteristic bands of polyurethanes: $\nu(\mathrm{NH})_{\text {assoc }}$ : $3314 \mathrm{~cm}^{-1} ; \nu\left(\mathrm{CH}_{2}\right)$ and $v\left(\mathrm{CH}_{3}\right)$ intermolecular hydrogen bonds: $2939 \mathrm{~cm}^{-1}$ and $2850 \mathrm{~cm}^{-1}$, respectively; $\nu(\mathrm{C}=\mathrm{O})_{\text {free. }}$ : $1720 \mathrm{~cm}^{-1}$ and $\nu(\mathrm{C}=\mathrm{O})_{\text {assoc. }}: 1705 \mathrm{~cm}^{-1}$ of urethane groups; $\delta(\mathrm{NH})_{\text {free }}: 1540 \mathrm{~cm}^{-1} ; \nu(\mathrm{CO}-\mathrm{N}): 1415 \mathrm{~cm}^{-1} ; \nu(\mathrm{COO})$ (ester fragments of urethane group) $1250 \mathrm{~cm}^{-1}$; and $v(\mathrm{C}-\mathrm{O}-\mathrm{C})$ (of flexible segments of the matrix): $1105 \mathrm{~cm}^{-1}$. The highfrequency shoulder at the peak of the stretching vibrations of NH groups in the IPU spectrum $\left(3375 \mathrm{~cm}^{-1}\right)$ indicates the presence of free $\mathrm{NH}$ groups. In the spectrum of IPU/10Xa (Figure 1(a)), this shoulder disappears, and the intensity of hydrogen-bonded $\mathrm{NH}$ groups $\left(3314 \mathrm{~cm}^{-1}\right)$ increases. A redistribution of the intensities of free $1720 \mathrm{~cm}^{-1}$ and bonded $1705 \mathrm{~cm}^{-1} \mathrm{CO}$ groups is observed. The appearance of lowfrequency shoulder $\left(1031 \mathrm{~cm}^{-1}\right)$, which refers to the stretching 


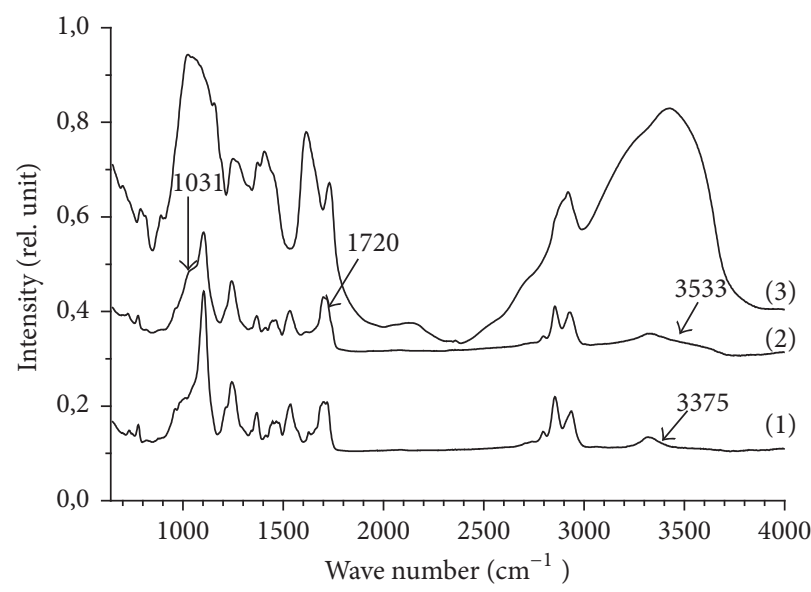

(a)

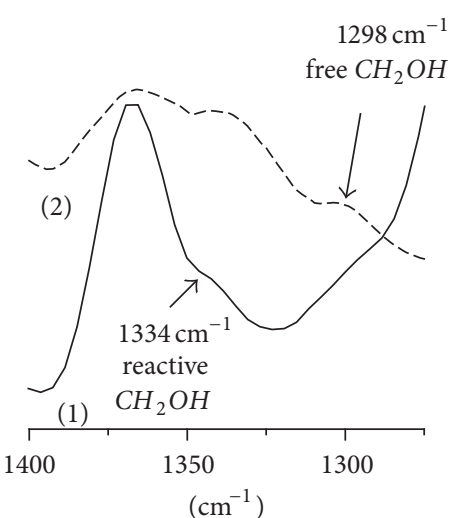

(b)

Figure 1: IR spectra: (a) IPU (1), IPU/10Xa (2), and Xa (3); (b) IPU /10Xa (1) and Xa (2).

vibrations of $\mathrm{C}-\mathrm{O}$ and decrease of intensity of the valence symmetric vibrations of C-O-C $1105 \mathrm{~cm}^{-1}$ (Figures 1(a) and 2 ), indicates the hydrogen association of ether oxygen of polyurethane with $\mathrm{OH}$-groups of Xa. The appearance of a broad weak band at $3533 \mathrm{~cm}^{-1}$ is associated with the presence of free $\mathrm{OH}$ groups of $\mathrm{Xa}$.

At the same time, the appearance in the spectrum of the IPU/Xa (Figure 1(b), curve (1)) of the band at $1334 \mathrm{~cm}^{-1}$, assigned to the $\mathrm{C}-\mathrm{H}$ bond of $\mathrm{CH}_{2} \mathrm{OH}$ group, with intensity lower than that for the native $\mathrm{Xa}$ and absence of the band $1298 \mathrm{~cm}^{-1}$ (Figure 1(b), curve (2)), indicates the participation of these groups in the formation of a chemical bond with the NCO groups of ionomeric oligourethane.

3.5. DMA Results. The temperature dependencies of $\tan \delta$ и $E^{\prime}$ and viscoelastic characteristics for the IPU and IPU/Xa films are shown in Figure 2 and Table 2. The dependence $\tan \delta-T$ (Figure 2(a)) for the IPU is typical for segmented polyurethanes: there are two relaxation processes, corresponding to the soft and hard blocks. The maximum in the temperature range of -70 to $10^{\circ} \mathrm{C}\left(T_{g}=-30^{\circ} \mathrm{C}\right)$ corresponds to the IPU soft blocks' relaxation transition. In the same temperature range, a sharp drop of $E^{\prime}$ (Figure 2(b)) is observed. Sharp peak of $\tan \delta$ at $90^{\circ} \mathrm{C}$ and sharp drop of $E^{\prime}$ higher that $70^{\circ} \mathrm{C}$ indicate the existence of hard block in IPU.

Such viscoelastic behavior is inherent to many segmented IPU. This is due to the segmental mobility in the hard blocks' microregions (hard domains) and their destruction. The relaxation transition typical for the soft block of IPU is also observed for all IPU/Xa films along with the fixed beginning of the relaxation transition for the hard block (Figure 2(a)). However, the viscoelastic behavior of the IPU/Xa is significantly affected by incorporation of Xa. The increase of Xa content results in significant lowering of the relaxation peak corresponding to the soft block and in $T_{g}$ reduction (Table 2). Thus, $30 \%$ of Xa content (IPU/30Xa) leads to lowering of $T_{g}$ by $20^{\circ} \mathrm{C}$ in regard to $T_{g}$ of IPU.
TABLE 2: Viscoelastic characteristics of xanthan containing IPU.

\begin{tabular}{lccc}
\hline Xa content, \% & $\begin{array}{c}T_{g},{ }^{\circ} \mathrm{C} \\
\left.\text { (according to } \tan \delta_{\max }\right)\end{array}$ & $\tan \delta_{\max }$ & $\begin{array}{c}E^{\prime}, \mathrm{MPa} \\
\left(25^{\circ} \mathrm{C}\right)\end{array}$ \\
\hline 0 & -30 & 0,54 & 6,5 \\
5 & -42 & 0,21 & 136 \\
10 & -45 & 0,18 & 247 \\
30 & -50 & 0,09 & 1230 \\
\hline
\end{tabular}

Such changes in relaxation behavior may be caused by three-dimensional Xa molecules which form steric hindrances during the IPU/Xa soft block formation. It leads to its partial destruction and $T_{g}$ lowering. At the same time, the decrease of specific weight of IPU/Xa soft-segmented part and interaction between the polar groups of the IPU and the $\mathrm{OH}$ groups of $\mathrm{Xa}$ results in the blocking of flexible polymer chains mobility and, consequently, decreasing $\tan \delta_{\max }$. The relaxation transition corresponding to the hard block of IPU/Xa begins at higher temperatures compared to IPU matrix and is characterized by a smoother increase of mechanical loss factor (Figure 2(a)). Possibly the destruction of hard domains in IPU/Xa is preceded by the gradual destruction of intermolecular hydrogen bonds between the $\mathrm{OH}$ groups of $\mathrm{Xa}$ and urethane and urea groups of IPU. When Xa content amounts to $30 \%$, the growth of mechanical loss factor is not observed up to $240^{\circ} \mathrm{C}$. Perhaps a significant increase in the proportion of bound urethane groups at such Xa concentration leads to a sharp restriction or complete blocking of segmental mobility in the hard block. The lowintensity relaxation maxima on the temperature dependence of $\tan \delta$ indicate the heterogeneity of the IPU/Xa systems and the presence of amorphous microregions with different compositions. Incorporation of $\mathrm{Xa}$ results in substantial increase of storage modulus (Figure 2(b)). Thus, at $T=25^{\circ} \mathrm{C}$, the value of the storage modulus for IPU/5Xa is more than 20 times higher than that for the pure IPU. When the content of Xa reaches $30 \%$ (IPU/30Xa), the value of storage modulus increases almost in 200 times (Table 2). Such significant 


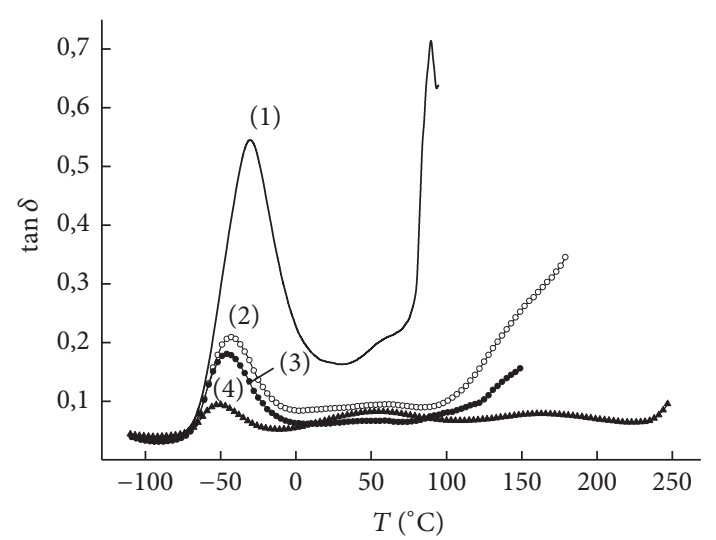

(a)

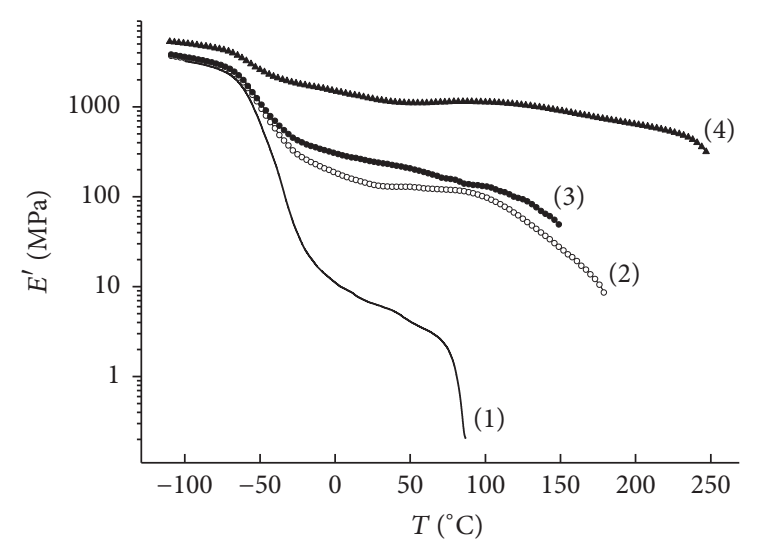

(b)

FIgURE 2: Temperature dependence of $\tan \delta$ (a) and $E^{\prime}$ (b) of IPU matrix (1), IPU/5Xa (2), IPU/10Xa (3), and IPU/30Xa (4).

increase of the storage modulus of Xa-comprising IPUs confirms the presence of chemical and hydrogen bonding between the components.

Thus, viscoelastic properties of IPU/30Xa are determined by Xa content and intermolecular interactions between the components.

3.6. Acid and Alkaline Hydrolysis. The presence of $\mathrm{Xa}$ in the IPU chain determines the nature of hydrolysis, one of the main factors of the materials' degradation under environmental conditions. The higher the Xa content, the greater the mass loss and the lower the strength and elasticity of the films after hydrolysis (Table 3); that is, IPU/Xa films are more susceptible to hydrolytic destruction in comparison with the IPU matrix.

The IPU/Xa (bio)degradation ability was studied by a technique that allows us to simulate the processes taking place under the natural conditions [20]. Samples were incubated in containers with soil of medium biological activity $(\mathrm{pH}=$ 6.82 , relative humidity: $60 \%, T=14-25^{\circ} \mathrm{C}$ ) for a period of 1-4 months [21]. The analysis of the soil's bacterial population has shown the presence of fungi of the following genera: Rhizopus, Aspergillus, and Penicillium.

The rate of degradation was controlled by weight loss of incubated samples through regular intervals. The higher the Xa content, the greater the mass loss of the samples (Table 4), and within 4 months it reaches $10.2 \%$ (IPU/5Xa) and 38\% (IPU/30X a), which exceeds the actual Xa content and the specified matrix characteristic. This indicates the possibility of control of destruction rate by changing the component composition.

Soil-born microorganisms (MO) affect the films' properties. They provoke a decrease of physic-mechanical parameters $(\sigma / \varepsilon)$ after remaining 4 months in the soil: for IPU matrix by $2.8 / 1.4 \%$, for IPU/5Xa by $50.1 / 18,0 \%$, respectively, and for IPU/10Xa and IPU/30Xa; these indices are not available, because the films have lost their integrity. Thus, the presence of Xa promotes biodegradation of polymer materials. Visual assessment of the films after testing in the soil also indicates a sufficiently high degree of samples' damage with MO.

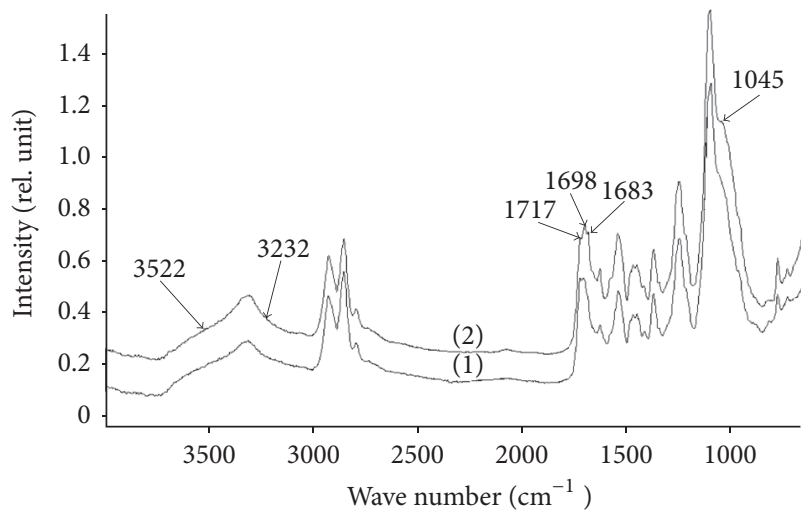

FIGURE 3: IR spectra of IPU/10Xa before (1) and after (2) incubation into the soil for 4 months.

The degradation of the samples was confirmed by IR spectroscopy on the example of IPU/10Xa. Figure 3 shows IR spectra of IPU/10Xa before (1) and after (2) incubation into the soil. In the absorption region $(1000-1800) \mathrm{cm}^{-1}$ of the after-ground sample (spectrum 2), a redistribution of the intensities of the bonded $1698 \mathrm{~cm}^{-1}$ and free $1717 \mathrm{~cm}^{-1} \mathrm{C}=\mathrm{O}$ groups is observed. The appearance of a new band $1683 \mathrm{~cm}^{-1}$ is associated with the decomposition of $\mathrm{COOH}$ groups: the ester group turns into an ether one. In addition, the expanse of the $\mathrm{OH}$ - groups' band to the more $\left(3522 \mathrm{~cm}^{-1}\right)$ and less $\left(3232 \mathrm{~cm}^{-1}\right)$ frequency region is observed. The appearance of a new band $1045 \mathrm{~cm}^{-1}$ is a result of the ether bonds decomposition after sample incubation in the soil.

3.7. Thermodestruction. The processes of thermal destruction of IPU and IPU/Xa, a comparative analysis of their structure, and the depth of (bio)degradation in the soil were estimated by the PMS method.

Analysis of the temperature dependence of the total ion current of the emission of volatile degradation products of the IPU (Figure 4(a)) has shown its complete thermal decomposition in two stages with maximum decomposition rates at the 
TABLE 3: Physic-mechanical characteristics of the IPU, IPU/Xa films after acid and alkaline hydrolysis.

\begin{tabular}{|c|c|c|c|c|c|c|}
\hline \multirow[b]{2}{*}{ Xa content, \% } & \multicolumn{3}{|c|}{$0,1 \mathrm{~N}$ solution of $\mathrm{KOH}$} & \multicolumn{3}{|c|}{$0,1 \mathrm{~N}$ solution of $\mathrm{HCl}$} \\
\hline & Weight loss, \% & $\begin{array}{c}\text { Tensile strength } \\
\sigma, \mathrm{MPa}\end{array}$ & $\begin{array}{c}\text { Elongation at a break } \\
\text { point, } \varepsilon, \%\end{array}$ & Weight loss, \% & $\begin{array}{c}\text { Tensile strength } \\
\sigma, \mathrm{MPa}\end{array}$ & $\begin{array}{c}\text { Elongation at a break } \\
\text { point, } \varepsilon, \%\end{array}$ \\
\hline 0 & 0,1 & 5,7 & 970 & 0,22 & 6,7 & 860 \\
\hline 5,0 & 1,8 & 1,3 & 442 & 1,7 & 1,7 & 402 \\
\hline 10 & 3,3 & $*$ & $*$ & 3,4 & $*$ & $*$ \\
\hline 30 & 10,6 & * & $*$ & 11 & $*$ & $*$ \\
\hline
\end{tabular}

* Fragmentation of the film.

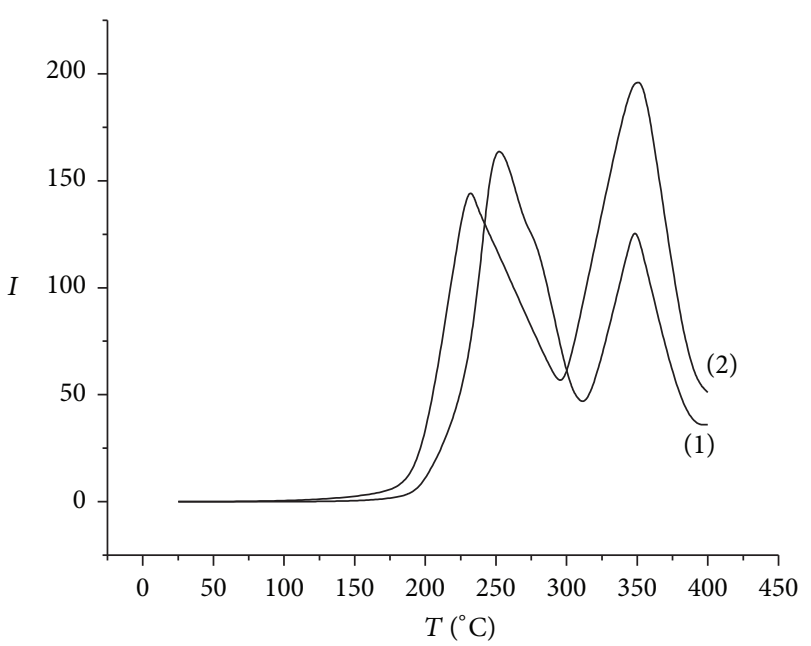

(a)

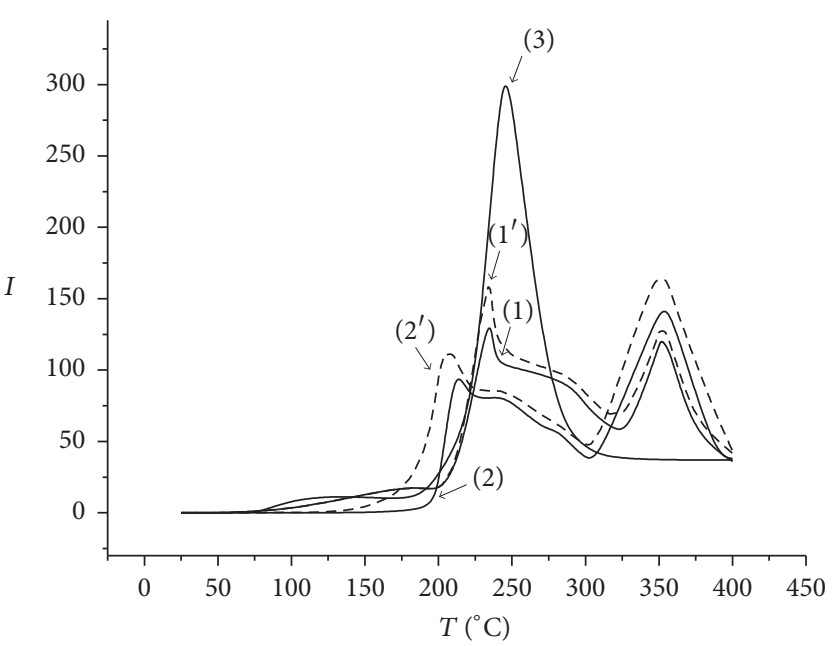

(b)

FIGURE 4: The temperature dependence of the ion current intensity for IPU (a), IPU/10Xa $(1,2)$, and IPU/30Xa ( $\left.1^{\prime}, 2^{\prime}\right)(\mathrm{b}):\left(1,1^{\prime}\right)$ initial sample; $\left(2,2^{\prime}\right)$ sample after incubation in the soil (4 months); (3) initial Xa.

TABLE 4: Results of of IPU/Xa incubation in the soil.

\begin{tabular}{lcccc}
\hline $\begin{array}{l}\text { Characteristic } \\
(4 \text { months })\end{array}$ & 0 & 5,0 & 10,0 & 30,0 \\
\hline $\begin{array}{l}\text { Weight loss, } \% \\
\begin{array}{l}\text { Changing of } \\
\text { physic-mechanical indices } \\
\text { after the test }(\sigma / \varepsilon), \%\end{array}\end{array}$ & 1,3 & 10,2 & 13 & 38 \\
& $2,8 / 1,4$ & $50,1 / 18,0$ & $*$ & $*$ \\
\hline
\end{tabular}

${ }^{*}$ Fragmentation of the film.

temperatures of $250^{\circ} \mathrm{C}$ and $350^{\circ} \mathrm{C}$, which corresponds to the decomposition temperatures of hard and soft blocks. The first stage corresponds to the pyrolysis of urethane and urea bonds and the second to the pyrolysis of oligoether fragments [22]. The maximum of the peak of IPU kept in the soil shifts to the lower temperature $\left(220^{\circ} \mathrm{C}\right)$ and is supplemented by a decrease of the intensity of the decomposition peak of hard blocks. The maximum decomposition peak of soft blocks remains at the same temperature of $350^{\circ} \mathrm{C}$; however, the intensity of the total ion current of volatile products is significantly increased. Thus, keeping the IPU films in the soil results in the primary degradation of oligoether component, since it is known [23] that the oligoether fragments are predominantly situated in the IPU surface layers. In the initial IPU/10Xa (Figure 4(b)), the high intensity of the volatile products' release is observed at the hard blocks' decomposition and is accompanied by the release of water, as well as the following fragments: $\left(m / z: 28\left(\mathrm{CO}, \mathrm{C}_{2} \mathrm{H}_{4}, \mathrm{~N}_{2}, \mathrm{CHNH}\right), 31\left(\mathrm{CH}_{3} \mathrm{O}, \mathrm{CH}_{2} \mathrm{OH}\right)\right.$, $\left.\left.\left.43\left(\mathrm{C}_{2} \mathrm{H}_{5} \mathrm{~N}\right), \mathrm{C}_{3} \mathrm{H}_{7}\right), \mathrm{CH}_{3} \mathrm{CO}\right), 55\left(\mathrm{C}_{4} \mathrm{H}_{7}\right), \mathrm{CH}_{2} \mathrm{CHCO}\right), 71$ $\left(\mathrm{CH}_{2} \mathrm{CHCH}_{2} \mathrm{CHO}\right)$, and $\left.73\left(\mathrm{OHCCH}_{2} \mathrm{CHOH}\right)\right)$, which are the pyrolysis products of urethane and urea groups. With the increase of Xa content (sample IPU/30Xa), the intensity of release of the volatile products of the hard block decomposition increases (Figure $4(\mathrm{~b})\left(1^{\prime}\right)$ ). After the incubation into the soil, similar to IPU, a greater intensity of volatile products' release is observed at the decomposition of the soft blocks for both IPU/10Xa and IPU/30Xa. The shift of the maximum $\left(350^{\circ} \mathrm{C}\right)$ is not observed. For the incubated IPU/10Xa and IPU/30Xa samples, the temperature of the maximum intensity of the release of volatile decomposition products of the hard block is shifted towards the lower temperatures, from 230 to $210^{\circ} \mathrm{C}$ for IPU/10Xa and from 230 to $200^{\circ} \mathrm{C}$ for IPU/30Xa.

The dependence of the ion current on temperature for Xa has only one maximum at $250^{\circ} \mathrm{C}$ (Figure $4(\mathrm{~b})$ ). The fragments with $\mathrm{m} / z 18$ and 44 , corresponding to water and carbon dioxide, have the maximum specific content. It should be noted that there are practically no fragments typical for the degradation of native $\mathrm{Xa}\left(\mathrm{m} / z 15\left(\mathrm{CH}_{3}\right), 17(\mathrm{OH}), 32\left(\mathrm{O}_{2}\right)\right.$, 


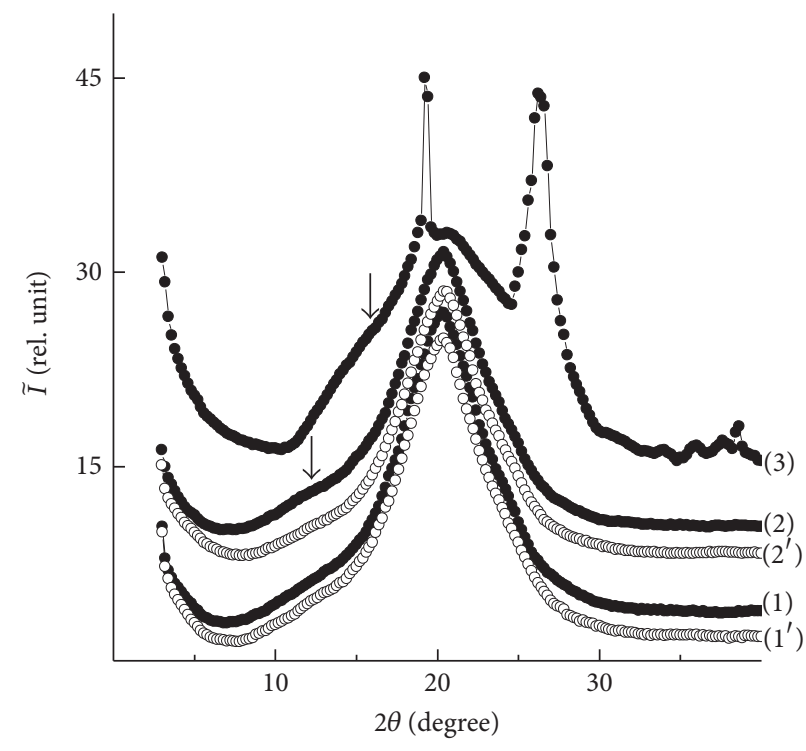

(a)

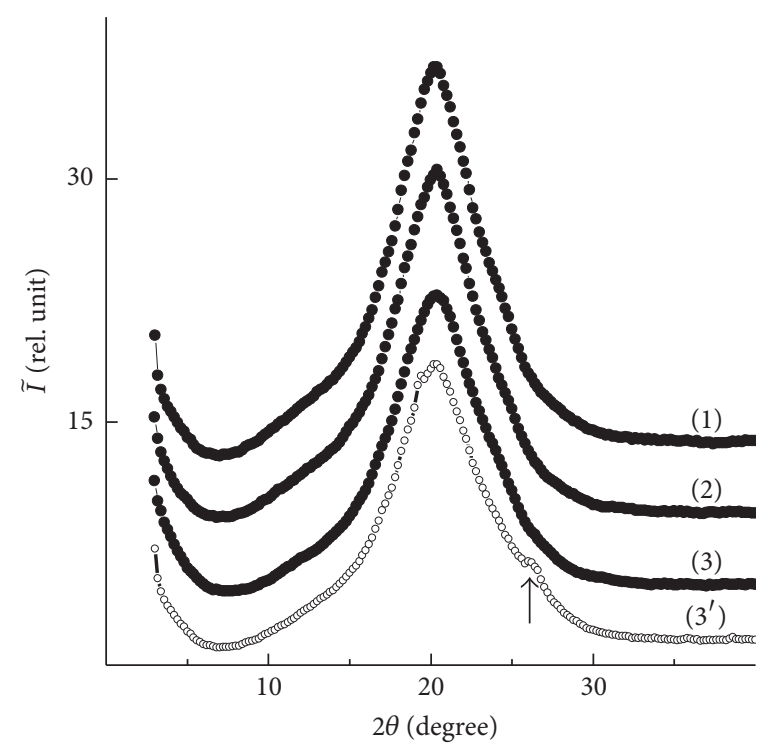

(b)

FIGURE 5: WAXS patterns of IPU and Xa-containing IPU: (a) initial IPU (1), IPU/5Xa (2), Xa (3), and being exposed in a soil for 4 months: IPU $\left(1^{\prime}\right)$ and IPU/5Xa $\left(2^{\prime}\right)$; (b) initial IPU (1), IPU/5Xa (2), and IPU/10Xa $\left(3,3^{\prime}\right)$ : (3) experimental and $\left(3^{\prime}\right)$ additive.

and $\left.60\left(\mathrm{CH}_{2} \mathrm{CO}_{2} \mathrm{H}\right)\right)$ among the degradation products of IPU/10Xa and IPU/30Xa, which indicates the chemical binding of Xa. As it follows from the temperature dependence, the destruction of the IPU hard block occurs with higher intensity in comparison with the IPU/10Xa and IPU/30Xa, which may be a result of intra- and intermolecular hydrogen bonding between $\mathrm{OH}$ groups of $\mathrm{Xa}$ and urethane and urea groups of IPU. Therefore, the destruction of intermolecular hydrogen bonds precedes the destruction of the hard blocks and results in the decrease of the IPU/Xa hard blocks' decomposition intensity. However, the higher the Xa content, the lower the degradation temperature.

3.8. X-Ray Analysis. The presence of a single diffuse diffraction maximum with angular position $2 \theta_{\mathrm{m}}=20,3^{\circ}$ in WAXS patterns of IPU and IPU/5Xa (Figure 5(a), curves $(1,2)$ ) shows that these polymers are characterized by short-range order at the translation in expanse of their macrochain fragments.

The average distance $(d)$ between the centers of macromolecular chain layers of IPU and IPU/5Xa, according to the Bragg equation $d=\lambda(2 \sin \theta)-1$ (where $\lambda$ is the wavelength of the $\mathrm{CuK}_{\alpha}$ radiation $\lambda=0,154 \mathrm{~nm}$ ), amounts to $0.437 \mathrm{~nm}$.

Two discrete diffraction maxima, singlet and multiplet at $2 \theta_{m}=19,3^{\circ}$ and $26,2^{\circ}$, respectively, appeared against a background of evident asymmetric diffraction peak $2 \theta_{m} \approx$ $20,6^{\circ}$ in WAXS pattern of Xa (Figure 5(a), curve (3)), testifying to the amorphous-crystalline structure of Xa.

Nonlinear change of scattering intensity in the range of $2 \theta \sim 11.2^{\circ}-17.0^{\circ}$ is indicated by poorly detected diffraction maximum at $2 \theta_{m} \sim 15,8^{\circ}$ (arrow). This maximum describes the short-range order at the translation in the Xa volume of its side branch fragments.
We evaluated the relative level of crystallinity $X_{\mathrm{cr}}$ of polysaccharide $\mathrm{Xa}$ in accordance with Matthews's method [24], $X_{\mathrm{cr}} \approx 20 \%$, and determined effective size $L$ of $\mathrm{Xa}$ crystallites using Scherer method [25], $L \approx 18 \mathrm{~nm}$.

The amorphous-crystalline structure of $\mathrm{Xa}$ was not detected on the X-ray diffraction pattern of IPU/5Xa and IPU/10Xa (Figure 5(b), curve $(2,3)$ ), due to intermolecular interaction between components. Comparison of experimental and calculated additive (when interaction between components is absent) X-ray diffraction patterns of IPU/10Xa (Figure 5(b), curves $\left(3,3^{\prime}\right)$ ) has served as evidence that the absence of Xa crystalline structure phenomenon in IPU/Xa composition is caused by intermolecular interactions between IPU and Xa components.

Calculated additive X-ray diffraction pattern of IPU/10Xa (Figure 5(b), curve $\left(3^{\prime}\right)$ ) has shown that in case of the absence of components' interaction there is a weak expression of the most intense diffraction peaks (at $2 \theta_{m}=19,3^{\circ}$ and $26,2^{\circ}$ ) that characterize the crystalline structure of Xa. This is a conformation of intermolecular interactions between IPU and Xa which results in suppression of Xa capacity for crystallization.

The invariable intensity and angular position of the amorphous halo $\left(2 \theta_{m} \approx 20,3^{\circ}\right)$ of the initial and aged in the soil IPU and IPU/5Xa samples (Figure 5(a), curves $\left(1,1^{\prime}\right)$ and $\left.\left(2,2^{\prime}\right)\right)$ indicate that there is no change in their amorphous structure.

For more complete structural characterization of the initial 13 and aged for 4 months in the soil IPU and IPU/5Xa samples, we study their microheterogeneous structure. SAXS results (Figures 6(a) and 6(b)) have shown that all studied polymers have microheterogeneous structure. There are the areas of microheterogenity in their volume, the electron density $(\Delta \rho)$ between which is different from zero, $\Delta \rho=$ 


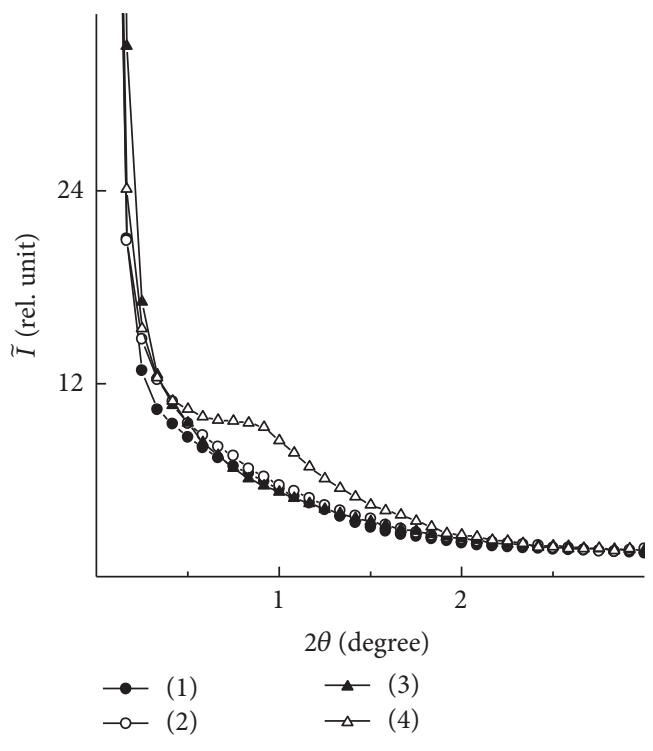

(a)

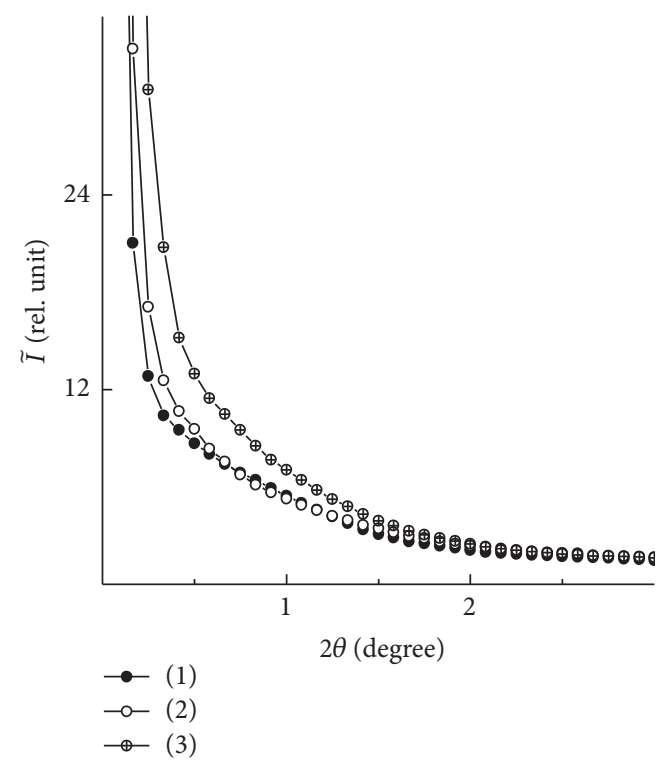

(b)

FIGURE 6: SAXS patterns of IPU and Xa-containing IPU: (a) initial IPU (1) and IPU/5Xa (2), and being exposed in soil for 4 months: IPU (3) and IPU/5Xa (4); and (b) initial IPU (1), IPU/5Xa (2), and IPU/10Xa (3).

$\rho-\langle\rho\rangle$, where $\rho$ and $\langle\rho\rangle$ are the local and average value of the electron density in two-phase system.

The comparison of the profiles of the initial and aged for 4 months in soil IPU and IPU/5Xa samples has shown that the initial IPU has the lowest scattering intensity as a result of thermodynamic incompatibility between soft and hard IPU units [26]. The sample IPU/5Xa has a slightly higher scattering intensity than the IPU. Even higher scattering intensity and, correspondingly, the value of the electron density contrast have the sample IPU/10Xa. At that the lack of interference maximum on the intensity profiles indicates a disordered placement of microareas of heterogeneity in polymer volume (Figure 6(b)). Attention is drawn to the fact that exposure of samples to soil for 4 months results in a growth of scattering intensity of both IPU and, particularly, IPU/5Xa. The appearance of the interference maximum $2 \theta_{m} \approx 0,92^{\circ}$ in a form of "shoulder" (Figure 6(a), curves $(3,4)$ ) indicates the existence of periodicity in distribution of microareas of heterogeneity with different size of local electron density in IPU/5Xa volume. According to the above Bragg equation, the value of period $D$ of alternation in the volume of monotype $\rho$-sized microareas of heterogeneity is $9.6 \mathrm{~nm}$. It should be noted that the increase of the SAXS intensity at the transition from IPU to IPU/5Xa and IPU/10Xa, as well as the result of exposure of the first two samples for 4 months in soil, characterizes the variations of the level of heterogeneity of their structure. To quantify the relative level of heterogeneity of the structure, we calculated the structural parameter "Porod invariant" $Q^{\prime}$ [27], the value of which is independent (invariant) of the form of microareas of heterogeneity:

$$
Q^{\prime}=\int_{0}^{\infty} q \widetilde{I}(q) d q
$$

where $q$ is directed magnitude of wave vector $s(q=2 \pi s)$.
TABLE 5: Parameters of microheterogeneous structure of initial IPU, IPU/5Xa, IPU/10Xa and IPU, IPU/5Xa after 4 months of exposure in soil.

\begin{tabular}{lcc}
\hline Sample & $\mathrm{Q}^{\prime}$, rel. unit & $l_{p}, \mathrm{~nm}$ \\
\hline IPU & 5,9 & 6,5 \\
IPU/5Xa & 6,4 & 5,4 \\
IPU/10Xa & 7,8 & 6,1 \\
IPU, 4 months in soil & 6,5 & 5,8 \\
IPU/5Xa, 4 months in soil & 7,8 & 5,3 \\
\hline
\end{tabular}

This parameter characterizes the integral intensity of Xray scattering by two-phase system and has a direct connection with the quadratic fluctuation of electron density in its volume.

According to calculated values of $Q^{\prime}$ (Table 5), IPU possesses the least level of structure heterogeneity, while IPU/10Xa and IPU//5Xa, which are kept for 4 months in soil, have the largest level of structure heterogeneity.

Another characteristic of microheterogeneous structure of studied systems is the average size of microareas of heterogeneity existing in their volume. The range of heterogeneity $l_{p}$ was determined by the Ruland method [28]. This parameter is directly related to the average diameter of the microareas of heterogeneity in the two-phase system. It was determined that presence of Xa results in a decrease of the effective size of microareas of heterogeneity both in the initial samples and after 4 months of exposure in soil (Table 4). Unlike the level of heterogeneity $Q^{\prime}$, the transition from IPU to IPU/5Xa and IPU/10Xa causes, in general, the reduction of the range of heterogeneity $l_{p}$ (Table 4 ).

Thus, as a result of X-ray study, Xa has been found to miss its ability to crystallization due to the intermolecular 
interactions between components in IPU/Xa systems. The increase of Xa content in IPU/Xa systems reduces the size of microareas of heterogeneity. The disappearance of the diffraction maximum $\left(2 \theta_{m} \approx 12,2^{\circ}\right)$ after exposure of the sample IPU/5Xa in the soil indicates a change of its amorphous structure as a result of (bio)degradation following a consecutive increase of structure heterogeneity on nanosized level.

\section{Conclusions}

New ecologically friendly IPUs were prepared on the basis of the renewable exopolysaccharide Xa. Introduction of $\mathrm{Xa}$ allows partially replacing exhaustible oil row materials and improving the strength properties of pure IPU matrix: the tensile strength of IPU/Xa systems is 1-5 times higher compared with IPU. Along with retention of other functional characteristics of the IPU, Xa imparts it a property of (bio)degradation after the end of lifetime that leads to the deep chemical transformations occurring in the IPU/Xa systems. The proven covalent and hydrogen bonding between components ensures the occurrence of destructive processes of the entire system as a whole. With an increase of Xa content, the mass loss of IPU/Xa systems as a result of hydrolytic splitting and degradation in the soil increases and exceeds the actual content of $\mathrm{Xa}$ and the value of mass loss of the IPU matrix. The results of PMS, DMA, and Xray scattering indicate that the presence of $\mathrm{Xa}$ in polymer macrochain leads to the formation of a new structural organization different from the structure of the IPU matrix due to the chemical bonding between the exopolysaccharide and diisocyanate. The structural and operational properties and degradability of studied polymers are determined by the structure and content of the natural component. Filmforming aqueous polyurethane dispersions on the basis of exopolysaccharide $\mathrm{Xa}$ are perspective as biologically active substances in agriculture: immunostimulants and protective coating for seeds and plants; antitranspirants for reducing water scarcity and optimization of the production process of crops in drought conditions; and binders for biologically active substances granulation. The advantages of such material lie in environmentally friendly production technology due to the absence of organic solvent, economy through the use of cheap renewable raw materials, and reducing the harmful impact on the environment through the regulated level of (bio)degradation after the expiration of life time.

\section{Conflicts of Interest}

The authors declare that there are no conflicts of interest.

\section{References}

[1] S. Rogovina, K. Aleksanyan, E. Prut, and A. Gorenberg, "Biodegradable blends of cellulose with synthetic polymers and some other polysaccharides," European Polymer Journal, vol. 49, no. 1, pp. 194-202, 2013.
[2] S. A. Ashter, "Overview of biodegradable polymers," in Introduction to Bioplastics Engineering, pp. 19-30, Elsevier, Amsterdam, Netherlands, 2016.

[3] T. Travinskaya and Y. Savelyev, "Aqueous polyurethane dispersions-sodium alginate based blends and hydrogels," Frontiers in Heterocyclic Chemistry, vol. 2, no. 1, pp. 20-25, 2016.

[4] P. Alagi, Y. J. Choi, and S. C. Hong, "Preparation of vegetable oil-based polyols with controlled hydroxyl functionalities for thermoplastic polyurethane," European Polymer Journal, vol. 78, pp. 46-60, 2016.

[5] M. J. Donnelly, J. L. Stanford, and R. H. Still, "The conversion of polysaccharides into polyurethanes: A review," Carbohydrate Polymers, vol. 14, no. 3, pp. 221-240, 1991.

[6] J. G. Southwick, H. Lee, A. M. Jamieson, and J. Blackwell, "Selfassociation of xanthan in aqueous solvent-systems," Carbohydrate Research, vol. 84, no. 2, pp. 287-295, 1980.

[7] S. C. Moldovenau, Analytical Pyrolysis of Natural Organic Polymers, vol. 20, Brown \& Williamson Tobacco Corp., Macon, Ga, USA, 1998, p. 510.

[8] T. V. Travinskaya, A. N. Brykova, I. K. Kurdish, A. V. Chevychalova, and Y. V. Savelyev, "Degradable ionomer polyurethane on the basis of xanthan," Reports of the Academy of Sciences, vol. 7, pp. 132-139, 2014.

[9] Y. V. Savelyev, T. V. Travinskaya, L. A. Markovskaya, and A. N. Brykova, "The method of obtain of degradable polymer composition," Pat. No 93372 Ukraine, Publ. 25.09.2014. Bull. no. $18,2014$.

[10] Q. B. Meng, S.-I. Lee, C. Nah, and Y.-S. Lee, "Preparation of waterborne polyurethanes using an amphiphilic diol for breathable waterproof textile coatings," Progress in Organic Coatings, vol. 66, no. 4, pp. 382-386, 2009.

[11] V. Sriram, S. Sundar, A. Dattathereyan, and G. Radhakrishnan, "Synthesis and characterization of cationomeric AB crosslinked polyurethane polymers based on different chain extenders," Reactive and Functional Polymers, vol. 64, no. 1, pp. 25-34, 2005.

[12] J. Bullermann, S. Friebel, T. Salthammer, and R. Spohnholz, "Novel polyurethane dispersions based on renewable raw materials-Stability studies by variations of DMPA content and degree of neutralisation," Progress in Organic Coatings, vol. 76, no. 4, pp. 609-615, 2013.

[13] T. Travinskaya, Y. Savelyev, and E. Mishchuk, "Waterborne polyurethane based starch containing materials: preparation, properties and study of degradability," Polymer Degradation and Stability, vol. 101, no. 1, pp. 102-108, 2014.

[14] S. J. Lee and B. K. Kim, "Covalent incorporation of starch derivative into waterborne polyurethane for biodegradability," Carbohydrate Polymers, vol. 87, no. 2, pp. 1803-1809, 2012.

[15] Y. V. Savelyev, T. V. Travinskaya, L. P. Robota et al., "Biodegradable polyurethane materials of different origin based on natural components," Austin Journal of Biomedical Engineering, vol. 2, no. 1, article 1030, 2015, http://www.austinpublishinggroup.com/.

[16] ASTM D2572-03, "Standard test method for isocyanate groups in urethane materials or prepolymers," ASTM, West Conshohocken, Pa, USA, 2003.

[17] S. Y. Shegolev and V. I. Klenin, "Determination of parameters of complicated disperse polymer system from turbidity spectrum," Vysokomolekulyarnye Soedineniya B, vol. 13, no. 12, pp. 28092815, 1971.

[18] T. V. Travinskaya, A. N. Brykova, V. I. Bortnitskiy, and Yu. V. Savelyev, "Preparation and Properties of (bio)degradable 
ionomer polyurethanes based on xanthan," Polymernyj Journal, vol. 36, no. 4, pp. 393-400, 2014.

[19] N. I. Levchenko, S. A. Sukhorukova, and T. V. Travinskaya, "Aqueous anionactive polyurethanes for high-quality coatings," in Proceedings of the Partnership in Polymers, the Cambridge Polymer Conference, pp. 195-200, Cambridge, UK, 1996, Special conference issue of full papers.

[20] B. S. Lee, M. Vert, and E. Holler, Water-Soluble Aliphatic Polyesters: Poly(malic acid)s, Wiley-VCH Verlag Gmbh, Weinheim, Germany, Polyester, 1st edition, 2002.

[21] I. P. Babaeva and G. M. Zenova, Biology of Soils, Moscow University, Moscow, Russia, 1989.

[22] V. A. Zaikin, Mass Spectroscopy of Synthetic Polymers, AllRussian Mass Spectrometric Society, Moscow, Russia, 2009.

[23] V. V Boyko, L. V. Kobrina, S. V. Riabov, and R. L. Gaiduk, "Investigation of biodegradable properties of polyurethane compositions filled by chitosan," Polymernyj Journal, vol. 26, no. 4, pp. 235-238, 2004.

[24] J. L. Matthews, H. S. Peiser, and R. B. Richards, "The X-ray measurement of the amorphous content of polythene samples," Acta Crystallographica, vol. 2, no. 2, pp. 85-90, 1949.

[25] A. Guiner, Radiography of Crystals. Theory And Practice, Nauka, Moscow, Russia, 1961, p. 604.

[26] V. I. Shtompel and Y. Y. Kercha, Structure of Linear Polyurethanes, Nauka, Moscow, Russia, 2008, Kiev, p. 248.

[27] G. Porod, in General Theory, Small-Angle X-Ray Scattering, O. Glatter and O. Kratky, Eds., pp. 17-51, Academic Press, Cambridge, Mass, USA, 1982, London.

[28] R. Perret and W. Ruland, "Eine verbesserte Auswertungsmethode für die Röntgenkleinwinkelstreuung von Hochpolymeren," Kolloid-Zeitschrift \& Zeitschrift für Polymere, vol. 247, no. 1-2, pp. 835-843, 1971. 

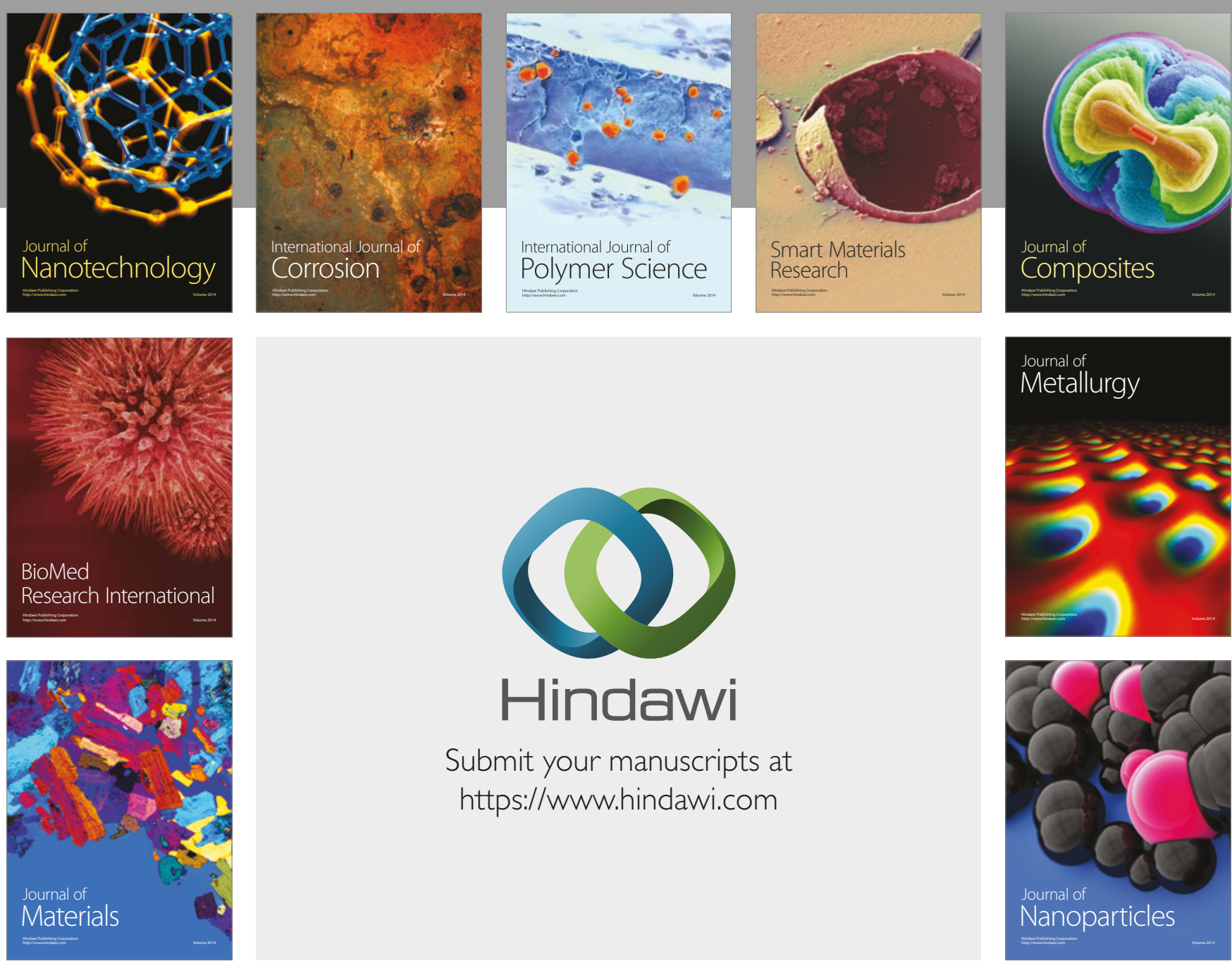

\section{Hindawi}

Submit your manuscripts at

https://www.hindawi.com
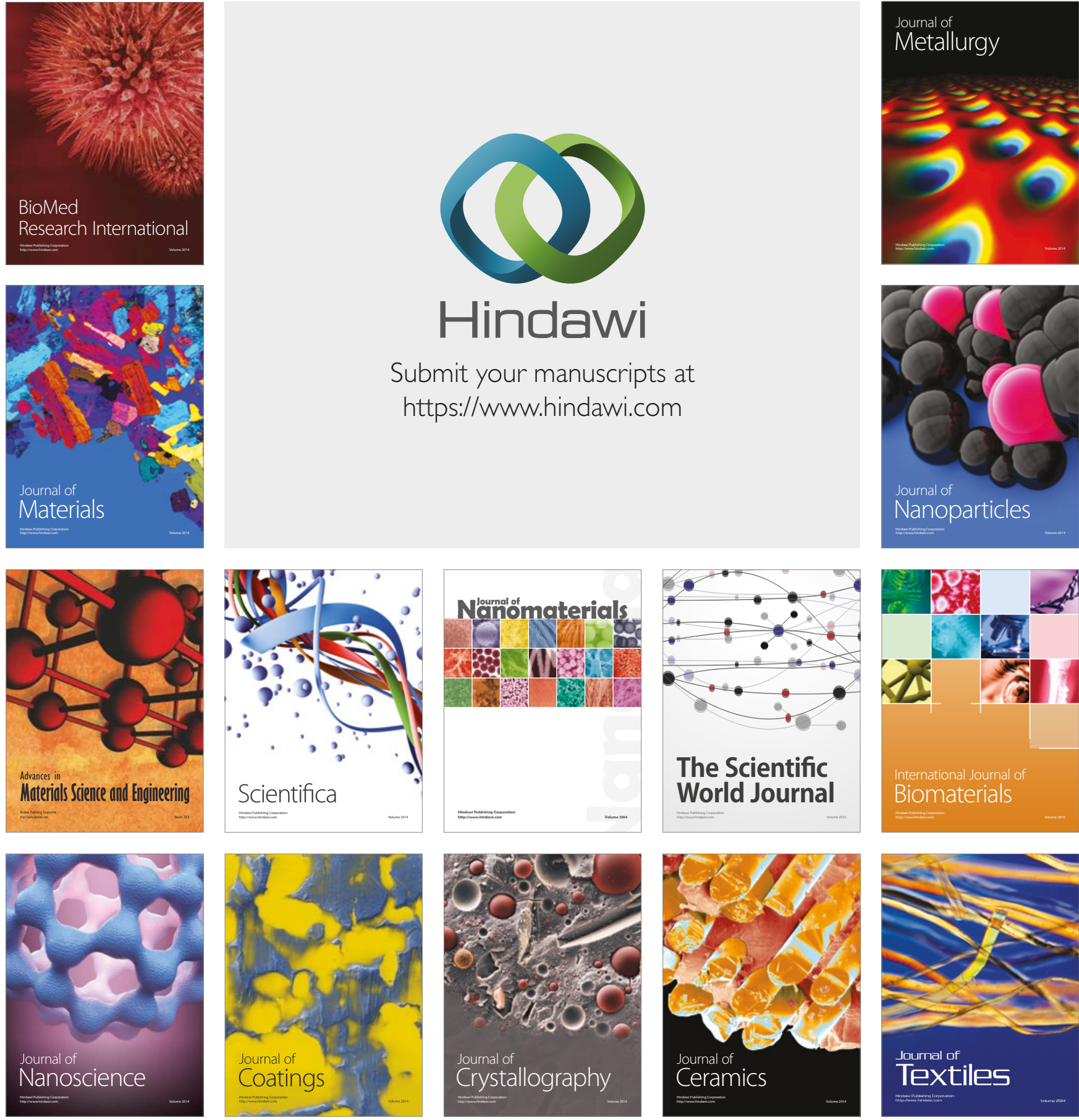

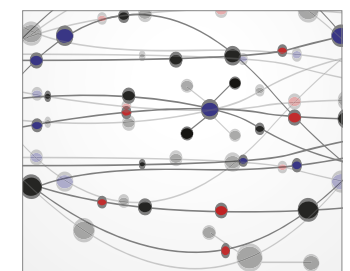

The Scientific World Journal
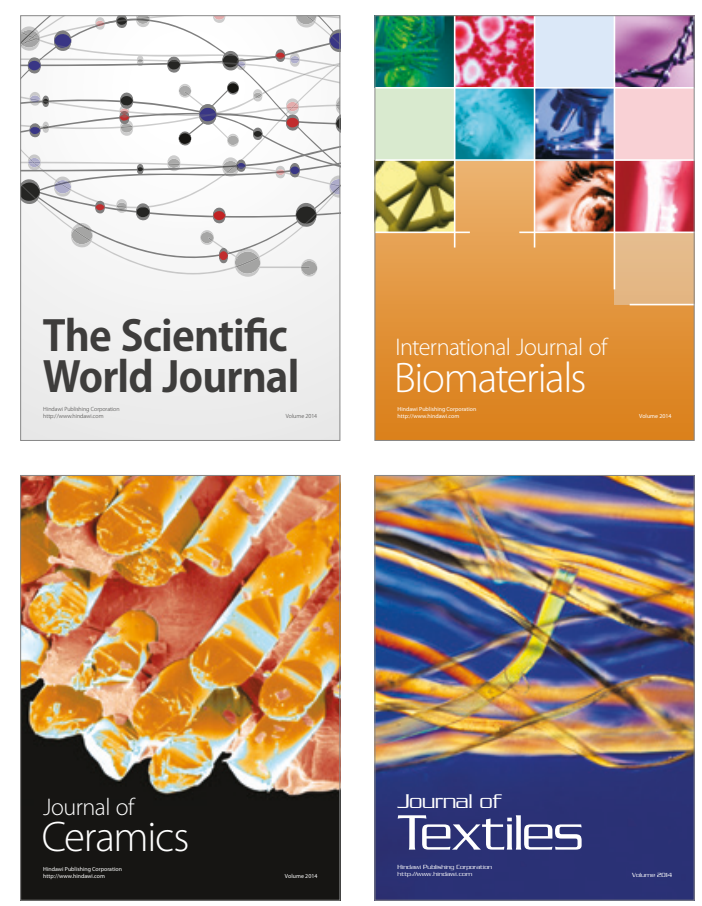